\title{
6. What sort of town is Fitzroy Crossing? Logistical and boundary problems of the 2006 enumeration in the southern Kimberley
}

\section{Kathryn Thorburn}

Fitzroy Crossing is a major service centre in the central western Kimberley. The nearest towns are Derby, 250 kilometres to the west, and Halls Creek, 290 kilometres to the east (see Figure 6.1). The majority of residents in Fitzroy Crossing are Indigenous, and there are a significant number of Indigenous-run non-governmental organisations (NGOs), including Marra Worra Worra (MWW) and Bunuba Inc., which, at the time of the census, were funded by the Western Australian and Commonwealth governments to service town-based Indigenous communities and outstations.

Fig. 6.1 Fitzroy Crossing and surrounding region

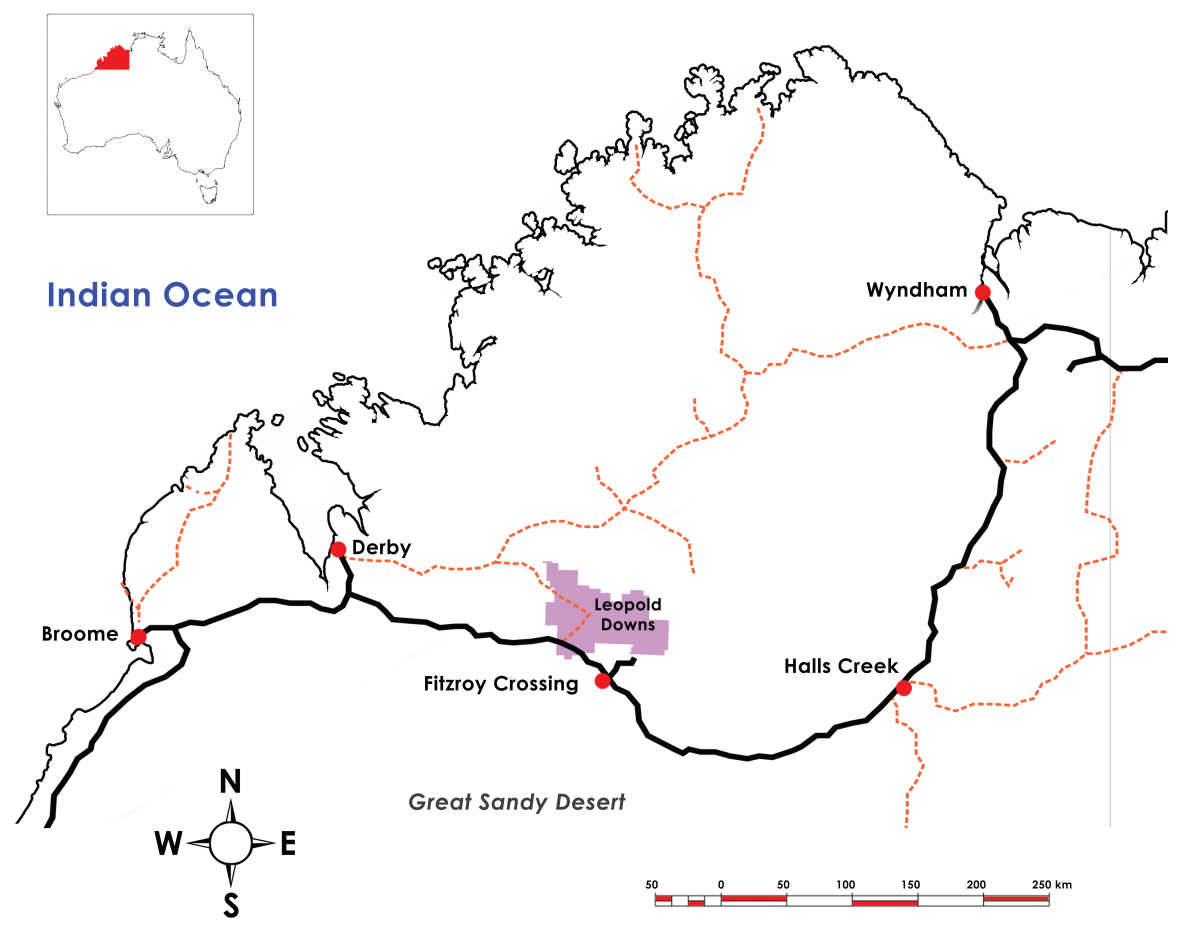


There are also a large number of non-Indigenous residents: about 45 per cent, according to the 2001 Census. Many of these non-Indigenous people work in service industries - health, education, administration and the like - as well as in various trades. Because Fitzroy Crossing is a town that services surrounding communities and pastoral stations in an area known as the Fitzroy Valley (estimated population 3500), there is much movement into and out of the town. In a sense, therefore, the 'population' of the town is rather unstable, and fluctuates seasonally and on the basis of various events such as festivals or funerals.

In addition, the Indigenous population of Fitzroy Crossing internally contains significant linguistic and cultural diversity. There are five major language groups resident in the town - Walmajarri, Wangkatjunga, Gooniyandi, Nyikina and Bunuba - as well as others, such as Djaru and Mangala. Bunuba are the traditional owners for the country on which Fitzroy Crossing sits. They have been associated with Bunuba Inc. since 1999, and before that with Junjuwa Community Inc. MWW has historically looked after the interests of non-Bunuba language groups in the town and on outstations and communities throughout the Fitzroy Valley.

While the brief of this research was to observe the effectiveness of the Indigenous Enumeration Strategy (IES) in capturing Indigenous residents in the town of Fitzroy Crossing, the 'mixed-up' nature of sections of the town meant I inevitably crossed paths with the mainstream, non-Indigenous count and collectors.

In its analysis of census data, the Australian Bureau of Statistics (ABS) separates out three 'discrete Indigenous communities' from the Fitzroy Crossing data: Junjuwa, Kurnangki and Mindi Rardi. In these areas of the town, the non-Indigenous population sits at less than 1 per cent of the total. For these areas, applying the IES would be predicted to be fairly unproblematic. Many other parts of the town - considered as distinct communities by their residents - are also enumerated under the IES. These are not separated out in the ABS's analysis but are incorporated into the 'discrete Indigenous communities' already mentioned, probably because their populations are too small. These include Burawa, Bungardi, Darlngunaya and Loanbung.

It is also noteworthy that the communities in which the IES is applied are characterised by their particular leases - mostly Aboriginal Lands Trust (ALT) reserves - which means that their municipal services, housing and so forth are managed by an Indigenous organisation, rather than by the local Derby/West Kimberley Shire. In Fitzroy Crossing, the two organisations in question are Bunuba Inc., which services Junjuwa, Burawa, Bungardi and Darlngunaya, as well as other outstations on the pastoral leases of Leopold Downs, and MWW, which services Kurnangki, Mindi Rardi and Loanbung in town, but also looks after 30 or so other communities throughout the Fitzroy Valley. These two organisations represent the primary point of articulation for outside interests 
wishing to engage with these Indigenous communities. As such, their role is vital in achieving community interest in the process and in providing resources including storage space, transport for census workers and other forms of support to ensure the census rolls out smoothly.

Those Indigenous people not living in the communities described above - that is, living in parts of town that were not on ALT leases or reserves-were enumerated along with the non-Indigenous population. These parts of the town included the town site itself, other peripheral areas around the town, such as blocks on either side of the river to the town's north, and an area adjacent to the school. Some of the houses in these areas are privately owned or rented; others are houses owned by local NGOs, which are leased to other such organisations for their staff. In the town itself, there are two streets in particular that are for public housing, and many local Aboriginal families live in this part of the town. According to the Western Australian Department of Housing and Works Derby office, there were at least 35 Aboriginal families living in this public housing at the time of the 2006 Census - that is, 35 separate households. This figure was the minimum number of Indigenous households that were enumerated with the mainstream, but the figure was likely to be higher, especially because of the number of houses that were owned by local Indigenous corporations, and that were likely to have had Indigenous families living in them.

This study differs, then, from the other three reported on in this monograph on two fronts. First, because of the nature of Fitzroy Crossing, the IES and the mainstream approach literally bumped against one another, sometimes overlapping and sometimes not meeting up and hence leaving gaps. Second, unlike in the Northern Territory, the approach throughout Western Australia was to attempt to complete the Indigenous count in the week of 7-11 August, with a three-week mop-up period. As will become apparent, by the end of the count, it was looking more like a time-extended, rolling count than a standard one. The Fitzroy Crossing study is nevertheless comparable with the others across the various aspects of the count, such as the workability of the household forms, the approach to staffing and training, the role of the Census Field Officer (CFO) and so forth.

\section{Getting started}

By the time I arrived in Fitzroy Crossing in mid July 2006, the CFO had already made progress in recruiting collector-interviewers (CIs) and Community Coordinators (CCs). The first training session took place on 18 July. Because of the particular character of the town, it was decided that there would be two training sessions: one for those CIs and the CC collecting Bunuba people's forms, the other for the remaining language groups whose data collection was being managed by MWW. 
Two CCs were identified for the MWW communities, one of whom was also the Chief Executive Officer (CEO) of MWW; the other was a senior staff member of MWW. In other words, both already had full-time jobs in a very busy community organisation. Nevertheless, they were the two identified by MWW as most able to carry out the tasks. The brief of these two CCs did not include Bunuba people, who made up about 300 people in the town of Fitzroy, and who had been allocated their own CC to work out of the Junjuwa office. ${ }^{1}$

The MWW CC's catchment incorporated the constituents of MWW, which included the three non-Bunuba communities in 'town' and a number of surrounding communities and outstations. The structuring of the census very much reflected the authority of these two crucial NGOs - a division that also affected my observation to a degree, since there were two parallel management structures and hierarchies in action simultaneously in Fitzroy Crossing. My main focus was on those communities associated with Bunuba Inc., simply because of my historical familiarity with those people ${ }^{2}$ and vice versa. I did, however, remain in contact with the CCs at $\mathrm{MWW}$, and with the town-based Area Supervisor - who was concerned with the rest of the town - throughout the census period. ${ }^{3}$

\section{Training, planning and preparation}

The approach to Indigenous enumeration in Western Australia was 'standard' - that is, to attempt to count everybody, everywhere, in the same week. This was very different to the approach adopted in the Northern Territory, which was a 'rolling count' - that is, to train and then count, move to the next place, train and then count, and so on. I shall refer to the area covered by the $\mathrm{CFO}$ as the 'southern Kimberley' - an area stretching from Balgo and Mulan in the east to Jarlmadangah/Mt Anderson in the west, and incorporating the dozens of localities in between. ${ }^{4}$ The first step was to coordinate across this vast area and to organise training sessions for community members at semi-centralised locations. These training dates did not always eventuate- people might have had more pressing matters to attend to or might simply have forgotten. Already we seem to be seeing how the 'standard' count might not work. The time lags between the first, introductory visit-in which the CFO might meet the chairperson and make an administrator aware of a return date for training - and the return to train was problematic. The CFO, from the outset, therefore had to backtrack, to attempt again to train in communities that might have missed out

\footnotetext{
1 Junjuwa is the Fitzroy Crossing community with a majority Bunuba population and it is where the Bunuba Inc. office was located in 2006.

2 I spent the first six months of 2005 working with Bunuba Inc. as part of my doctoral fieldwork.

3 'Area Supervisor' is the ABS term for the non-Indigenous coordinators.

4 The distance between Mulan and Jarlmadangah is $780 \mathrm{~km}$, incorporating approximately $350 \mathrm{~km}$ of dirt road.
} 
on his first run. This pattern of backtracking - returning to places throughout his area to catch up - was to become quickly established. The size of the area, and the time required to drive between these communities - some of them, such as Balgo, are more than 300 kilometres of dirt road away from the main highway - clearly jeopardised the CFO's ability to coordinate the exercise.

It was not clear how much use had been made - or could have been made - of the report from the $\mathrm{CFO}$ of the 2001 Census. The $2006 \mathrm{CFO}$ commented that this report was not of much use, since the 2001 Census depended on collaborating with a number of smaller Community Development Employment Project (CDEP) organisations that had ceased to exist, so there was a vacuum in many localities at the organisational level. It was also notable that this same CFO had been involved in conducting the Community Housing and Infrastructure Needs Survey (CHINS) only two months before, yet the CHINS data seemed to have no role in informing the planning process for the census - for example, planning the number of forms (on average, one for each house) for each community. That fundamental matters such as the number of forms required had not been estimated before the count - so that forms were still being ordered from Perth during the official census week (8-11 August) — set the whole process back further.

\section{Training}

On the first training day in Fitzroy Crossing for Bunuba CIs, only three people came out of six who had been identified by the CC from Junjuwa. The training for MWW was the next day and was attended by two different Bunuba people to replace those who had not shown up the day before, and one of the original team. Fortunately, on both training days, the Bunuba Inc. vehicle was available to 'round up' people who had agreed to attend, as the training was between 5 and 10 kilometres away from people's home communities. Had this vehicle not been available, there could have been much poorer attendance. The MWW training was well attended and included both of the CCs already mentioned. As people accustomed to managing the intrusion of bureaucrats and other outsiders, they encouraged all the CIs present to ask questions - there certainly were many more questions on this second day than on the first. These two CCs also stated in the MWW training session that they were to be the contact people if any CIs encountered difficulties - they were both infinitely more available, via phone or in the office, than the CFO, who returned to Fitzroy Crossing only periodically. In any event, I reluctantly took on a similar role for Bunuba people, mainly in contacting the Perth Census Management Unit (CMU) when necessary, or attempting to follow up CIs' and CCs' inquiries with the CFO after hours, via phone, or when he was camping at Fitzroy Crossing, generally on his way to somewhere else. I was able to do this because, unlike the CCs and the CIs, I had a mobile phone; this meant that I could call the CFO after hours, but it also meant that he could call me after hours and leave a message to pass on to the Bunuba 
census team. A more thorough planning process would have considered what avenues for communication were available.

Even at this early stage of the process, the CFO was under pressure and was rushed; the training suffered as a result. The CC of Bunuba, for example, who was to be managing five other people and attempting to coordinate the enumeration of more than 100 households, received barely more training than did the CIs. Nor did she receive a Community Coordinator Manual, which probably would have been very helpful, especially the 'frequently asked questions' section. That the CFO was already rushing at this stage seems to have compounded other difficulties that arose later.

For example, there was little opportunity for questions during the training, and indeed few arose in the first session I attended-perhaps no surprise given that none of the CIs tried out the form on each other (as was supposed to happen). The training essentially consisted of watching the training DVD, followed by the CFO reading through the Interviewer Household Form (IHF) and then people filling out the various forms to enable them to be paid. As I did not observe the CFO training, I cannot comment on the adequacy of the CFO's own training in informing his understanding of some of the issues that would arise with particular questions. Critically, Questions 11 and 12 (see Appendix A), which attempted to distinguish between people who were away and people living and/or staying at a dwelling, were not well explained. In particular, people did not understand that those written down as normally here but away and unlikely to be counted elsewhere were supposed to be moved 'inside the form' to Question 12. I doubt a single form in any of the Bunuba communities was completed in this way - resulting in very limited information being collected for these residents. In any case, CIs were repeatedly unsure how to handle the various states of 'being a resident' that they encountered, and were quite relieved to leave people off (to be caught up with 'later', which often did not happen) when, for example, they were down at the supermarket, or doing contract mustering.

Part of the reason why the training was not especially effective, it seems to me, is that it did not succeed in contextualising the whole census exercise. There could have been greater effort in the DVD to demonstrate what the census information was used for-or, if not in the DVD, the CFO himself could have gone through some of the previous census data for that region, and for particular communities that people came from. In other words, it might be useful for people to consider what the impacts are when the count is not accurate in terms of a concrete example from their own community, which they can relate to. For example, 'If we do not count all the kids under the age of five living in Fitzroy Crossing now, then the number of kids in each of the classrooms will just keep getting bigger because the government won't know to send more teachers for us.' 
In addition, the training sessions took place on 18 and 19 July - that is, at least two weeks before any CIs started interviewing. Arguably, even if the training had been adequate, the CIs would still have forgotten some of the more subtle or tricky aspects of the form outlined in the training. Adopting the 'standard' approach - especially when it entails such a time lag between training and the real count - should require that there is an avenue for questions to be answered. Such an avenue might be provided by, for example, a toll-free phone number. The manual provided by the ABS was not referred to by any of the CIs I was observing, perhaps because very limited reference was made to it during the training.

Between the training and the beginning of the count in Junjuwa, the CFO and I went out with an older man and traditional owner for some of the station country to Leopold Downs Station to ascertain roughly how many people, and houses, might be on the pastoral excision communities. This seemed to be part of the brief of the $\mathrm{CFO}$ - that is, these particular outstations, but not the station itself. The station workers - that is, those living at the homestead rather than on pastoral excision communities - were not, however, considered part of the brief of the CFO, despite the fact that the station in question was owned by Aboriginal people. While there was a non-Indigenous manager there, he had five Indigenous people working alongside him and reckoned there were another five or so out on the stock camp. Enumerating these workers, as well as the non-Indigenous station staff, was, however, deemed to be the responsibility of the mainstream enumerator for the area. One can but wonder at the efficiency of having two different ABS staff visit the same station — which is some 60 kilometres from Fitzroy Crossing - the one to enumerate Indigenous communities there, the other to enumerate staff and workers, the majority of whom were in fact Indigenous.

\section{Managing the paperwork}

A crucial part of the planning was to establish the correct Master Dwelling Checklist (MDC) and draw from that the Interviewer Dwelling Checklists (IDCs) that were to guide the CIs. ${ }^{5}$ In the case of Bunuba, the CC did not understand this process, although the MDC for the largest community, Junjuwa, was begun with the CFO's help, on the basis of a map of Junjuwa provided by the Bunuba Inc. housing officer. All except one of the MDCs and related IDCs were drawn up along the way, or even after the count had been done, on the basis of the number of IHFs filled in for a particular community or outstation. The validity of the MDCs and IDCs as checking mechanisms after the fact was completely undermined - although in my observation they were in fact largely accurate, apart from one house that was missed on the MDC and the IDC and was not enumerated at all. The main reason, it seemed, why CIs filled in IDCs was their

\footnotetext{
${ }^{5}$ For a full description of the 'ideal' procedure in the field, see Chapter 1.
} 
understanding that it was on the basis of these forms that they were to be paid. Indeed, the CFO would never have realised that the IDCs and MDCs had been created after the count - rather than before it - if it had not been for the fact that the Collection District (CD) numbers to be filled in at the top right corner of each were missing. He had neglected to explain to the $\mathrm{CC}$ what these numbers were, or to provide her with the list for her area to ensure that none were missed.

The correct procedure was for the CFO to work with the CC in drawing up the MDCs, being sure to include the correct CD number and the correct regime of Census Record Numbers (CRNs). The CC was not, however, informed about CRNs until the data collection was complete, except for a handful of houses. The MDCs and IDCs were therefore drawn up yet again. Fixing the CRNs on the IHFs was a little trickier and required lots of scribbling out and, in some cases, necessitated filling out a whole new form.

The IDCs were very useful for identifying for the CC-who would follow up such things - if houses had been missed, for example, if there was no one at home at the time that the CI first called. It was, however, never clear to her, or to me, what the 'persons counted' boxes - for males and females - on the MDC and the IDC were for, when they were to be filled in, or by whom. Were they, for example, to be filled in by the ICs once they considered their interviewing work done, or by the CC once she and the CFO had checked the forms and made certain they were correct? It was also not clear whether they were to include visitors at the house in these totals, or people written down who were normally there, but who were away for the interview. This would, of course, have impacted on whether people were paid correctly.

\section{The role of the Census Field Officer}

The role of the CFO was absolutely pivotal in the success or otherwise of the 2006 Census. Indeed, it seems that the extent of responsibility placed on this individual in the whole process was a very risky strategy. There are a few elements to this burden that need to be unpacked. Firstly, the area to be covered by the CFO in question was significant. This vast area contains dozens of communities, some consisting only of a single family group, and some with highly variable occupancy. Obviously the CFO could not visit and coordinate all of these smaller places, so the approach was taken to engage with community-based organisations that provided services across the southern Kimberley. This engagement was, however, very informal and patchy. It involved the $\mathrm{CFO}$ having a chat with a councillor, chairman or administrator, identifying a CC, carrying out a morning's training, dropping off forms and then returning to pick up forms a few weeks later. The patchiness of these interactions was not always the CFO's fault: some of these organisation offices are not always staffed, so making contact by telephone to arrange a visit can be difficult. In addition, those community members trained to be CIs might not live in the community 
where the office is situated or might not have a telephone, and again, therefore, communication becomes problematic. In addition, the resources of these community-based organisations, and their staff, tend to be extremely overcommitted, and the lack of early engagement with these bodies meant that the census - and the requests to the CFO for assistance - was not always given priority.

In order to cover the ground he needed to cover, the CFO estimated that he was spending 50 per cent of his time driving. ${ }^{6}$ In my observation, the time he spent in any given community was highly variable. While some communities received only a morning's training, in others the CFO was present for a week or two, because he had to help with the count itself. Therefore, he had no capacity to monitor what was happening anywhere except where he was on the day, or to provide CIs or CCs with any support, should they need it. That is, he had responsibility for everything, but no capacity to be responsible across the entire area. While he did have a satellite phone, he checked messages only in the evening. Very few members of his 'team' across the southern Kimberley, however, had a phone number to leave for him to get back to them.

That he had to return regularly to Broome to pick up supplies - extra IHFs, hats, satchels and so forth - added enormously to his time on the road. Having a base where materials could be stored, and perhaps an administrative assistant in Fitzroy Crossing, would have freed him up enormously. As it stood, once the training was completed, it was never quite clear when the CFO might be returning to Fitzroy Crossing. There were no other contacts given to the census workers for ABS staff in the Perth CMU, so if they had any questions, or needs such as more forms, there was no option but to attempt to contact the CFO. As noted above, this process was by no means straightforward.

\section{The count}

The CFO encouraged the Junjuwa CIs to start the count a week early-a suggestion that made a lot of sense given their enthusiasm and my availability as an observer and as a logistical resource with a car and a licence, and the fact that the week before census week was 'slack week'. ${ }^{7}$ Since people's finances are getting low, there is generally much less drinking or mobility during slack week; people are easier to find and are less likely to be distracted by all of the activity that occurs during pay week; and there are less likely to be so many

\footnotetext{
6 Between 12 March and 29 September - that is, 29 weeks (the period including the earlier CHINS data collection) - the CFO travelled a distance of 34287 kilometres, an average of 1182 kilometres a week. Arguably, however, the fact that the CHINS stage was a lot more straightforward and required little or no backtracking suggests that most of this travel occurred during the census period - that is, in the final three months. The CFO also estimated that he was in Perth for at least two weeks of this time, for training.

7 Slack week is the week between pay weeks, although some people — such as pensioners — are paid in this 'in between' week.
} 
visitors in town for shopping. Of course, counting this community early raises questions about the potential for double-counting of people counted in Junjuwa and then counted again somewhere else in census week.

There were four CIs working in the community of Junjuwa and each was allocated 15 houses. In addition, there were a number of much smaller communities that this group of collectors was responsible for: Darlngunaya, Bungardi, Burawa, Biridu, Galamunda and Warangarri.

By and large, the CC took responsibility for these other communities, in part because I had a car and therefore she and I could go off and count those people. One young man was trained up to do the count in Darlngunaya, where he resided. This is the largest of the smaller communities, containing about 10 houses.

In the event, the real count began on 1 August. The $\mathrm{CC}$ and I drove around Junjuwa, finding the CIs, giving them their forms and the map on which the CC had allocated them particular areas. We then drove over to Burawa, a small community of about six houses, to begin the interview process. This was the first time the $\mathrm{CC}$ had attempted to fill in a form, since that process did not occur during the training. This first interview took 45 minutes, in part because the CC was trying to recall points made in the training video-two weeks earlier - about individual questions on the form.

In total, there were five CIs, one $\mathrm{CC}$ and myself engaged in the census for Bunuba Inc. Apart from the young man counting Darlngunaya, the four remaining CIs were in fact two couples, who worked together. This seemed a very effective arrangement for a range of reasons. One partner could act as a backup interviewer if there was a person in the house with whom the other partner had an avoidance relationship. One person might be far more confident in writing, so they could write the answers while the other asked the questions. Finally, it is more enjoyable and socially acceptable not to work alone.

One issue that arose was with people who worked full time. There were a number of houses that I visited with the CC where no one was home during the day. The CC herself was a mother of five children and, not owning a motor car, she was unable to chase up these people in the evening. The current approach seems to be based on the assumption that Indigenous people will be at home and available for interview during working hours, and does not seem to make provision for people in such communities who work full-time - apart from the CC or CI following them up after hours, which is not always possible if the census staff do not live in the same community. Such situations must surely arise regularly in Indigenous communities. In the end, the CC made the decision to leave a form at these households, to be collected later. 


\section{The effectiveness of having locals enumerating locals}

The problem with observational reporting is that it is not necessarily so obvious to the observer what is working well, as opposed to what is not working well, in the current system. An opportunity did arise, however, to observe a context in which the census process worked less well. Mindi Rardi is a largely non-Bunuba community in Fitzroy Crossing, which was MWW's responsibility in this context. The CC, however, offered to help out the MWW staff, so the four CIs from Junjuwa and I spent two mornings enumerating the people there. In general, the CIs were less comfortable working in this other community, even though they knew many people there. They were much keener to get forms over and done with quickly, and would not push people for answers. For example, the count of children in Mindi Rardi will be very much less than it should be, for the CIs would write down only the immediate response to the question 'Who stops here?', which often overlooked children. Others also would have been missed, since there was no follow-up or return visit to record people who happened to be at card games or at the supermarket on the day. While some of these people might have been noted when the forms were checked at MWW, those who were visitors would not have been recorded at all.

\section{Marra Worra Worra}

One of the CCs stated at the training that she hoped to have the parts of Fitzroy Crossing for which MWW was responsible completed by 3 August. After that date, she was going on leave for four weeks; however, the count for MWW's Fitzroy Crossing communities did not begin until well into the official census week, after 7 August. Part of the reason for the late start was that MWW still did not have enough forms (they were about 120 short) well into census week.

In any case, a single MWW staff member did most of the count of people in town at Kurnangki and Loanbung, as well as other communities such as Djimbalakudindj, about 100 kilometres to the west. By this time, this particular MWW staffer was acting CEO, so was having to carry out this work after hours.

\section{The 'visitor' question}

When people are really visitors - that is, when the are not just extended family members from outstations - for example, if they are in-laws from a different language group, the interviewers sometimes did not feel comfortable asking them the full range of questions. On one occasion, I was asked by the two CIs to enumerate a house of eight young people from as far south as Jigalong who were still in town after a funeral, and who were camping in one of the older houses at Mindi Rardi. In a sense, it was handy for the CIs to have someone like me around, a kind of neutral figure, to ask and explain these 'rude' questions to strangers in town. 


\section{The style of the count}

According to the CFO Field Manual, there are three types of enumeration: standard (the approach taken in the Kimberley), rolling and assisted. Arguably, while the first kind of approach worked sufficiently well in certain areas, the problem was that because there was absolutely no oversight in many communities no one was aware if nothing had been done until it was almost too late. Taking the third approach ${ }^{8}$ would have meant that the progress on the count could at least have been monitored. Taking the first approach and applying it across the board does not acknowledge the fact that there can be significant variations in human capacity across communities - a truism that might not be apparent to a CFO, especially one with a relatively short-term relationship with communities and community members. The approach, then, has potential to be very 'hit and miss'.

The intent with the census was that the majority of the southern Kimberley would be completed in some sense by the end of the week of 7 August. What ensued was that the CFO was still training in that week and that, for a significant number of communities, absolutely nothing happened once the training ended. Some very large communities were not enumerated until well into September when the CFO was joined by an ABS colleague from Perth and by two other CFOs who had finished their areas. The communities of Wankgatjungka, Yiyili, Looma and Jarlmadangah all required unplanned-for help from outside. My understanding was that the absolute deadline for forms to be 'in the mail' was 15 September, the date I was to leave Fitzroy Crossing. The count was, however, still under way when my observations ceased.

\section{Issues specific to towns of the Fitzroy Crossing type}

Although my brief was to observe the taking of the Indigenous part of the census, as already mentioned, I was aware that there were significant numbers of Indigenous people who lived in what is known as the 'town site'. The mixing up of people in certain areas should be relatively easy for the census to manage - it simply requires some form of continuing communication between the CFO and the non-Indigenous equivalent - the Area Supervisor - and some dedicated effort in the planning stage. As stated in the 2006 Census IES: 'For 2006, the role of the Census Field Officer in areas covered by Area Supervisors [mainstream managers] will be adjusted so that lines of responsibility and communication between these staff are clearer.' Regrettably, that did not occur, and not only did the CFO never even meet either of the Area Supervisors, the latter did not even meet each other! No 'Indigenous Assistants' were engaged

8 The assisted approach is defined in the IES thus: '(W)here people from the community are recruited and trained and then the Census is conducted in the community. The census is completed before the CFO moves on to the next community.' 
to help with either the enumeration of Fitzroy Crossing 'town site', or with the stations and tourists enumerator who was attempting to count people across a similarly huge area - one quite distinct from, yet overlapping in parts with, the CFO's area. The Area Supervisor in Fitzroy Crossing - a non-Indigenous woman but 'married-in' and resident for some 10 years - was aware that there were about 30 Indigenous households being enumerated in the mainstream collection. The Indigenous Assistant she thought she had recruited did not help out in the end, because she was already burnt out from working on the census at the nearby community of Bayulu. While the Perth ABS staff had encouraged the Area Supervisor to find an Indigenous Assistant to help out, in the end she was unable to.

Beyond the town of Fitzroy Crossing itself, there was much anecdotal evidence that similar issues were arising, such as that already mentioned relating to the pastoral stations. If census staff on the ground are not communicating with each other, and have been given the sense that they are not to collect from 'the other', significant gaps can easily emerge, as was the case. Overlaps can occur too, as when the CFO and the Area Supervisor on occasions visited the same stations, unaware of what the other was doing - this despite the fact that they were regularly camping at the same caravan park in Fitzroy Crossing. Arguably, the approach of enumerating Indigenous people separately has the potential to greatly improve the accuracy of the count, however, the process needs to be tempered with commonsense, so that, in some instances, the Indigenous CIs might also collect data from non-Indigenous people. The census will, of course, never be absolutely effective in these areas, but it seems that there are some quite simple matters to be remedied that would see it being a lot more effective next time around.

\section{Conclusion}

Undoubtedly, the 2006 Census count in Fitzroy Crossing took much longer and was more problematic than was planned for. Lack of planning and lack of resources - especially the very limited availability of the $\mathrm{CFO}$ - seriously undermined the efficiency of the exercise of census-taking across the entire area of this CFO's responsibility. There would clearly be a major benefit in terms of cost, efficiency and accuracy in devoting more time and resources to planning the census, with local NGOs, but also between ABS personnel (between the non-Indigenous and Indigenous census-takers), paying some considerable attention to the experience of previous census-takers.

The value of local knowledge cannot be overemphasised, and should be sought early in the planning process. Certain mobility trends, for example, are fairly predictable, such as the number of people-Indigenous and non-Indigenous - working in stock camps in August in the Kimberley. Others are less so, such as funerals, which might or might not be taking place locally 
but which will nevertheless impact enormously on mobility. What might be worth considering is more CCs to coordinate efforts on a smaller scale, and a long enough lead time for the ABS to recruit locals to fill these roles, including time for them to plan properly. Recruiting people who are not concurrently trying to do another full-time job might also increase the effectiveness of the count, although again such recruitment would probably require a longer lead time. An essential element of the planning is contingency planning - or planning for the unplanned. In other words, there needs to be more flexibility and scope built into the timetable to allow for unforeseen events. This CFO, for example, hit a bullock on the road to Billiluna in early September, which took him out of action for nearly a week at a very crucial time in the whole process.

The role played by local Indigenous organisations is also crucial. Sanders (Chapter 3) demonstrates clearly how a strategic engagement of the ABS with a local NGO can be extremely beneficial. Similarly, Taylor (Chapter 5) demonstrates how a lack of this engagement can undermine the effectiveness of the IES. These organisations are critical in two regards: as a source of day-to-day local knowledge and in terms of the support they can provide logistically - vehicles, office space, storage space and so forth. This recommendation, however, needs to be tempered by two issues. The first is that recent trends suggest the number of Indigenous community-based organisations - at least in remote Australia - are decreasing (see, for example, Taylor 2006b: 57); and changes to the CDEP program might see even fewer such organisations in the future. The ABS might want to consider how it could engage with remote communities that have no such administrative centre. The second issue is that not all of these organisations have the same resources and capacity-again, this is where contingency needs to be built into the planning, to account for those organisations whose capacity to provide support to the census process might be variable or limited. 